\title{
An Enhanced Electronic Voting System (EnEVoS) with Hybrid Authentication Technique
}

\author{
Margaret Dumebi Okpor \\ Department of Computer Science, \\ Delta State Polytechnic, Ozoro
}

\begin{abstract}
Elections are the bedrock of democracy and voting is one of the electoral processes that ensure the sustenance of democracy, political growth and democratic stability of any society. We have designed an Enhanced Electronic Voting System (EnEVoS) with a Hybrid Authentication Technique, which will reduce electoral malpractices and manipulation of results to its barest minimum. The implementation of this Enhanced Electronic Voting System (EnEVoS) in Nigeria will boost the integrity and image of Independent National Electoral Commission (INEC). The programs used to develop this system are VB.net, Java and MySQL. These packages make the Graphic Interface User friendly for even those with little or no computer knowledge.
\end{abstract}

\section{Keywords}

EnEVoS, Biometric Authentication, Database Security, INEC, VIN,

\section{INTRODUCTION}

One basic feature of democracy that cuts across all divides of people is the act of election. Democracy thus encourages individual freedom according to the rule of law, so that people may behave and express themselves as they choose. This not only gives people a chance to choose their leaders, but also to freely express their views on issues. In response to the 1948 Universal Declaration of Human Rights which puts import on the necessity of free elections, nations aim at new and improved voting procedures which are of relevance to elections in the 21 st century [8].

With the passage of time, voting, which was mainly manual, has been influenced by Information Technology, with debates arising about the relevance or not, of computerized/online voting [11]. Nevertheless, it is impossible to completely rule out the need for technology and electronic voting, with the growing number of eligible voters and manual ballot papers involved. [7] indicates that electronic voting is the next logical step in applying online information-gathering and retrieval technologies to e-government.

Elections are understood to be the key mainstay of democracy all over the globe and voting is one of the electoral routes that ensure the sustenance of democratic system in any civilization. The veracity of democratic system is primary to the veracity of election itself consequently the election system must be satisfactorily secured to survive a range of fraudulent behavior. Satisfactorily secured to survive a range of fraudulent behavior and must be sufficiently translucent and comprehensible that voters and candidates can accept the outcome of an election. Unsurprisingly, the Nigerian electioneering history is littered with examples of elections being maneuvered in order to change their outcome.

On May 29, 2009 Nigeria celebrated a decade of democracy.
Many Nigerians said it was not worth celebrating, because our electoral system is a flawed exercise. Our political and electioneering process is branded with so many irregularities, ranging from ballot box snatching, stuffing of ballot boxes, political killings, using of political thugs to harass opposing candidates and finally weaken the electoral process. This mainly, is due to the fact that electoral processes in Nigeria are done manually and the result of such manual electoral process inevitably produces questionable electoral results.

Elections in most developed nations of the world with enviable democratic platforms have over the years been conducted electronically and in these countries little or no setbacks follow the results of such elections as they are seen to be free, fair and credible.

The Nigerian general election of 2015 was the 5th quadrennial election to be held since the end of military rule in 1999; giving Nigerian the honour of electing the President and members to the House of Representatives and the Senate. The National Independent Electoral proposed a semi-electronic mean of voting through the introduction of the Biometric Voter Card Reader Machine (BVCR) by way of checking the irregularities in previous election. The elections which were scheduled to be held on 14 February 2015 was postponed to 28 March, mainly due to the poor distribution of Permanent Voter Cards as a result of the new policies and the introduction of the Voter Card Reader Machine. Second, was the time frame for the training of INEC Officials that would implement the use of the Card Reader Machine at the election poll and also to curb ongoing Boko Haram insurgency in certain North-Eastern States. The government closed its land and sea borders from midnight on 25 March until the end of the polling date.

However the Voter Card Reader Machine did its job in certain parts of the country while in most part failed. For instance we could recall the failure of the machine when the then First Citizen of this Nation His Excellency Dr. Goodluck E. Jonathan was at the poll to cast his vote and the Machine failed to read his finger prints and the old pattern of manual screening was employed after several times of trial. The election was extended to 29 March due to delays and technical problems with the biometric Card Readers and this gave room for irregularities in the final results.

The system used in the last election still gave room for irregularities in the results due to failure of card readers that were distributed to the various polling units across the Country. Although it helped to reduce some irregularities in terms of over voting as opposed to what we had in 2011 general elections.

The current system of electoral process adopted by Nigeria it is posed with the challenges of:

\section{- Registration of voters below the voting age.}


- There have been cases of multiple registrations since the Nigeria Voters Registration system does not have a centralized database, Voters can register at different polling unit.

- Absence of authentication means and validation

- Also in the last election there were failures of the card readers which can also lead to irregularities in the voting process.

As a result of these problems the need to provide a hybrid voting system that will counter some of the aforementioned problems of the existing Nigeria voting process becomes a major area of focus in this research work.

This research work is aimed at developing a state of the art Enhanced Electronic Voting System (EnEVoS) with a Hybrid Authentication Technique for general election in Nigeria. The objectives of the study are stated below:

a) To provide a system that ensures credibility in elections by preventing double voting due to the biometric authentication technique employed

b) To find an alternative to paper-based voting which help the government reduce the huge costs incurred in conducting elections.

c) To provide a system that enables voter's registration, accreditation and voting convenience from any part of the country without traveling home to their registration point or polling unit where their name appeared.

d) To provide a system that will automatically count the result of the election at the end of the election without unnecessary delays in the announcement of election results.

\section{REVIEW OF RELATED LITERATURE}

According to [7] Electronic voting (also known as e-voting) is a term encompassing several different types of voting, embracing both electronic means of casting a vote and electronic means of counting votes. Electronic voting technology can include punched cards, optical scan voting systems and specialized voting kiosks (including selfcontained direct-recording electronic voting systems, or DRE). It can also involve transmission of ballots and votes via telephones, private computer networks, or the Internet.

Nigeria is a federation of 36 states with a federal capital territory and it has 774 local governments, about 8,800 registration areas, 111,119 polling units, senatorial districts, federal constituencies, and the state constituencies. The general observation is that conducting elections that are free, fair, peaceful and credible in a country such as Nigeria given its size, large population, terrain, and ethno-religious diversity is a difficult assignment even under normal circumstances.

The 2015 Election propounded the laid down voting procedure with accreditation and verification of eligible voters using Emp5500 machine in the morning between the hours of $8 \mathrm{am}$ and $1 \mathrm{pm}$ of the Election Day. Accreditation and Verification are followed strictly by the election proper, The voters will line up to cast their votes by thumb printing for the candidate of their choice based on party logo. The Presiding officer (PO) will count the number on the line and a security personnel will stand as the last person to avoid people joining unnecessarily. After the last voter has voted, then voting process is said to be concluded, the Presiding officers in polling centers count the votes in the presence of all the party agents and some voters that are present and on the completion of counting and recording of the votes on Forms EC. 8A and/or EC. 8A (I) and (II), the PO shall put the original completed form (statement of Result of Poll from the Polling Unit) in a tamper-proof envelope(s). The PO proceeds immediately to the Collation Centre where election results shall be done at the levels depending on the type of election in the following order. This process is depicted in the figure 1 below:

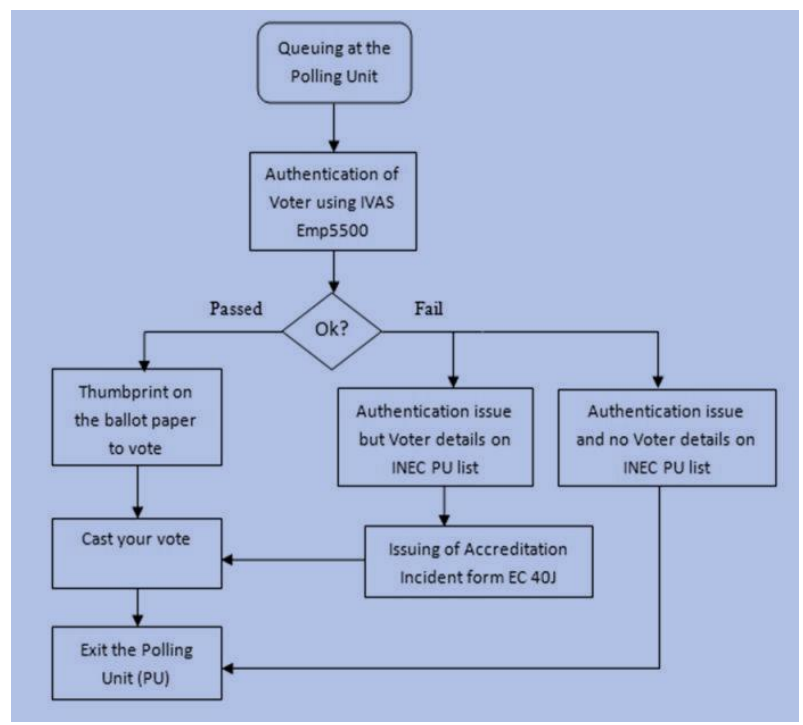

Fig 1: Pictorial illustration of the system of voting adopted by Nigeria.

(Systematic Evaluation of Semi-Electronic Voting System adopted in Nigeria 2015 General Elections)

Registration Area/Ward (RA/Ward) - Collation for all Elections

Local Government Area - LGA (Collation for all Elections

State Constituency (Collation and Declaration of State House of Assembly Elections)

Federal Constituency (Collation and Declaration of House of Representatives Elections)

Senatorial District (Collation and Declaration for Senatorial District Elections)

Governorship (Collation and Declaration for Governorship Elections)

Presidential (Collation and Declaration for Presidential Election.

At state level, E-Collation may be employed where election type and date is selected, delimitation parameter such bas State, LGA, Ward and PU is allowed to be selected too before entering publishing result after confirmation. After carefully checking through all the procedures involved listed above, we concluded that this is purely manual electoral processes with element of electronic voting in the areas of accreditation, verification and e-collation.

[17] in their work Systematic Evaluation of Semi-Electronic Voting System adopted in Nigeria 2015 General Elections on the American Journal of Information Systems; (2015) observed that owing to the fast progress of computer and communication technologies, many advanced services have been developed to take the advantages of the techniques. 
Among these services, electronic voting is a popular one since every voter can finish her/his voting process securely and rapidly but here in Nigeria, the electoral process is termed as Semi-Electronic voting system.

The author specified mainly on securing the voting system, by comparing the insecurities that exist in the manual voting system to that of the electronic voting system. Since the 1959 elections, which were the last to be supervised by the colonial authorities, all but one election has had its result contested. The only exception to this pattern was the June 121993 presidential election won by Chief M. K. O Abiola which was annulled by the Ibrahim Babangida military administration. All the previous elections from 1999 till 2011 are purely manual but that of 2015 embraced some elements of ICT in action.

General Muhammadu Buhari, who contested the 2003 presidential polls on the platform of All Nigerian Peoples Party(ANPP), describes the election as "a dark period in our history" contends that the elections were "characterized by large scale malpractices including rigging at all levels" Given the massive irregularities that attended the 2003 elections and the consequent legitimacy crisis they engendered, the 2007 and 2011 polls presented an opportunity for both the government and the election authorities to restore public confidence in the election process.

[3] identified some of the problems associated with electronic voting system and proposed an architecture that attempts to minimize its drawbacks while taking into consideration the social aspect of the populace and technical constraints in achieving a real e-voting system in Nigeria The architecture puts more emphasis on usability and data security while taking into consideration the highly decentralized nature of voting polls as well as the real time response of voters, the work also stated that the results of the web-based application implementation shows the great accuracy of the architecture in achieving successful election. However due to constraints associated to electronic voting system, the project recommends that INEC should review the standards of IT infrastructure in the country and develop more secure software before embarking on e-voting. The research places more emphasis on thorough review on the implementation of e-voting so as to address issues associated with its implementation in Nigeria. Recommendations were made on how to instantly update the election results visibly on the evoting system. This will help to avoid manipulations of results by any individual or party, as this will increase transparency and integrity. A proposal was made on a new e-exams system that uses data encryption in order to protect the questions sent to the e-Examination center through the internet or intranet and a biometric fingerprint authentication to screen the stakeholders [2].

[15] in his work listed of some of the problems and challenges of organizing and conducting an Election using the traditional Open Ballot System (OBS) and after the review of the manual system and electronic voting technologies, the study focused on the question - Is the internet voting sufficient for our voting processes and the work concluded that it is relatively impossible to develop an e-voting system that will satisfy all INEC specification of an e-voting system. Then, developed an e-voting system that is web based and also advised that before the implementation of the system, the entire system should be reviewed by INEC to ensure that it meets with certain standard of the INEC specification of an e-voting system. The work also identified and recommended that every citizen should be issued a citizen/national identification with which he/she can be uniquely identified, which will help in voters authentication. The research concluded that there is no doubt that a comprehensive electronic voting system will enhance the standard of elections in the state and the country at large, and that the veracity of all the people involved in the process determines the integrity of the system and the whole process and despite the potential advantages offered by e-voting, care should be taken as it may become a source of subversion rather than improving the current system.

\section{MATERIALS AND METHOD}

The objectives of the work is to design a system that will resolve the challenges that keep reoccurring in previous election resulting from multiple registration, registration of under age, over voting just to mention a few with the view of achieving free and fair elections. To achieve this system design the Rapid Application Development (RAD) model of System Developmental Life Circle was employed. RAD approaches to software development put less emphasis on planning tasks and more emphasis on development. In contrast to the waterfall model, which emphasizes rigorous specification and planning, RAD approaches emphasize the necessity of adjusting requirements in reaction to knowledge gained as the project progresses.

The programs used to develop this system are VB.net and MySQL, Java, PHP making the Graphic Interface User friendly enough for even those with little or no computer knowledge. The two major users of the design are the voters and admin. This can be seen architecture of the proposed system in Figure 2 below:

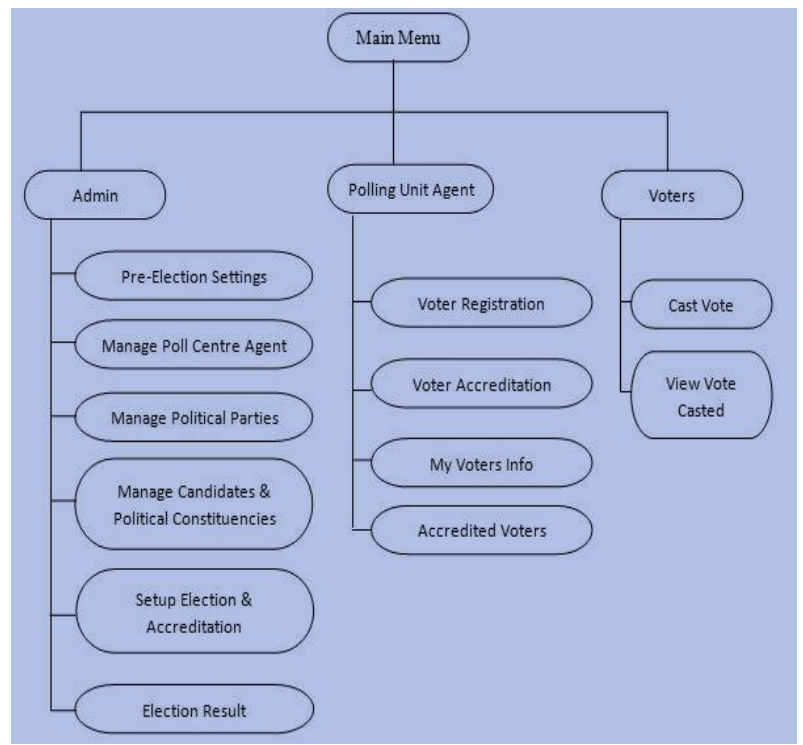

Fig 2: Architecture of the Proposed EnEVoS Model.

\section{Program Module}

The major modules of the system are broken into three:

1. Admin Module: The admin module is segmented into sections viz:

\section{Staff Authentication Setting}

This authenticates staff to use the System in order to perform most of the administrative task that are involved in the new system.

\section{Database Administrator}

Administrator has the privilege of viewing registered voters and editing their information, searching for a person (registered voter) by entering his name or VRN, can view the 
details of all voters who have registered. The administrator is also provided with the feature of election setup \& accreditation, viewing the information of voting i.e. numbers of accredited voters, numbers of valid voters, the all error log, view live results, though voters also have the privilege to view live results as the voting is taking place, which reduce the tendencies for rigging.

\section{Ballot Design}

This provides the administrator with the features of managing Political parties, candidates and political constituency by inserting candidate names into the ballot for respective categories (electoral position)and manifesto. The administrator can also update any candidates' profile or information by either editing or deleting information for respective categories of the election. After editing the setup the administrator can post the ballot for voting.

\section{Agents Module}

This form allows the administrator of the system to register the various officers that will manage each polling center during the registration and voting process and haven done that, assign them to various units across the nation by providing them with access detail of username and password for respective poll agent. On login, the agent is saddled with feature of voter registration and biometric accreditation during election. He can also view voter's information; make necessary correction if the need be and view numbers of accredited voters. It contains the following sections:

Voter Registration: This module is for the voter, where he/she must first register his/her details first into the registration form, fulfilling all the required specifications. If the validations are valid then only the information gets registered. Once the voter gets registered he/she is provided Voters Identity Number (VIN).

Voter Accreditation: This module allows agent to accredit voter through the biometric authentication mode and get access to the system in order to exercise their franchise.

3. Voters Module: This module is for the voters, where votes are cast.

\section{How Voting is Done with EnEVoS:}

After a voter has registered, a default password is sent to the telephone of each registered voter. During the voting, on the voting interface, voters are required to fill in their username and password correctly, which automatically takes them to the voting proper and once a voter has cast his or her vote for all the categories, i.e. for Presidential and Governorship and others, a voter cannot go back on this page to cast a vote again. Also without the biometric authentication accreditation one cannot gain access to cast his/her vote as part of the security measure put in place in case anyone has access to your VIN and password. Figure 3 shows a flowchart of the proposed system.

\section{Process Algorithm}

The Process algorithm for the exercise is given as follows:

Step 1: Launch the application

Step 2: Enter User Credentials and click on the login button

Step 3: On a Successful login

Step 4: Select Task Such as Voters Registration

Step 5: Enter Voters Information into the Registration Form

\section{Step 6: Click on the Next Button}

Step 7: The Biometric Finger Print Form Will Appear

Step 8: Capture the Finger print of the voters

Step 7: Click on Save

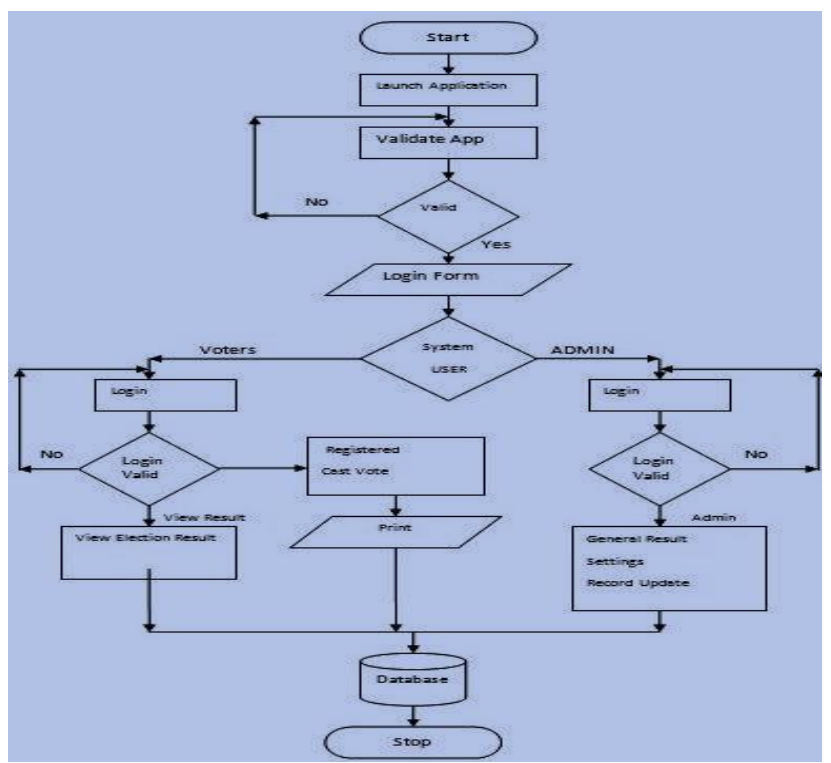

Fig 3: Flow chart for the Enhanced Electronic Voting System. (EnEVoS)

\section{RESULTS AND DISCUSSION}

The Enhanced Electronic Voting System (EnEVos) with a Hybrid Authentication Technique provides the necessary security by means of biometric authentication technique employed in determining a valid voter both at registration and accreditation in synchronization with either National Identity Number or Bank Verification Number details as opposed to the manual system of voting which allows for under age registration, multiple registration at different polling unit. This technique does not grant access to non-valid voters or unauthorized voter without the biometric authentication mode. This system also prevents voter from voting twice as opposed to the manual system that allows for multiple voting.

\section{System Security}

The security of the system is a one factor authentication using only the username and passwords to gain access to the application, also the security measures in the system also covers a cryptographic security measure using the encryption, hashing and salting techniques. So only authorized users are allowed to gain access to the system since the first form is the login form that asks for users login credentials.

\section{CONCLUSION AND RECOMMENDATION}

On the whole, the Enhanced Electronic Voting System (EnEVoS), if implemented by Independent National Electoral Commission (INEC) at both State and federal level, will go a long way in reducing the irregularities that have trailed our electoral processes over the year. However, this system must be carefully planned and implemented so that it can bring about a free and fair election. When this system is deployed, it will save time and reduce strenuous movement. The use of EnEVoS is sure to execute more credible election because it is accurate, effective and reliable. 
Therefore, we recommend the following:

INEC should review the standards of ICT infrastructure in the country and develop more secure databases and networks before embarking on e-voting.

$\square \quad$ There should be adoption of distributed encryption techniques for the purpose of secured data transmission.

There should be use of biometric capturing devices, which will serve as a means of voter's authentication.

There should be adequate and proper public enlightenment before the system is fully implemented.

More research should be made on this area to develop mobile application

\section{REFERENCES}

[1] Aditya, R. et al. (2004.) Implementation Issues In Secure E-Voting Schemes, Proceedings Of The Fifth Asia Pacific Industrial Engineering And Management Systems Conference

[2] Adebayo. O. and Abdulhamid S. M. (2010). Exams System for Nigerian Universities with Emphasis on Security and Result Integrityll, Book of Proceedings of TheSeventh International Conference on eLearning for Kowledge-Base Society. Held at Bangkok Metropolitan Area, Thailand. Page 47.1-47.11.2010.

[3] Animashaun K (2010): Regime Character, Electoral Crisis And Prospects Of Electoral Reform In Nigeria. Journal Of Nigeria Studies Volume 1, Number 1, Fall 2010.

[4] Benaloh, J. \& Tuinstra, D. (1994). Receipt-Free SecretBallot Elections, In Proceedings Of The 26th Acm Symposium On Theory Of Computing (Stoc'94), Montreal, Canada, Pp. 544-553.

[5] Benoit, D. K. (2004). Experience with Voting Overseas.Appendix 2J to the first Report Of Ireland's Commission On Electronic Voting.

[6] Brennock, M. (2004). Cabinet to Press Ahead On EVoting In EU And Local Polls. The Irish Times.

[7] Buchsbaum, T. (2004). E-Voting: International Developments And Lessons Learnt". Proceedings Of Electronic Voting In Europe Technology, Law, Politics And Society. Lecture Notes In Informatics. Workshop Of The Esf Ted Programme Together With Gi And Ocg.
[8] Caltech-Mit. (2001). Voting: What is, What Could Be. Cal Tech-Mit Voting Technology Project Report Www.Vote.Caltech.Edu/ Reports.

[9] Cetinkaya, O. \& Cetinkaya, D. (2007). Towards Secure E-Elections In Turkey: Requirements And Principles, International Workshop On Dependability And Security In E-Government (Desegov'07) - In Proceedings Of Ares'07, Vienna, Austria, Pp. 903-907.

[10] Chaum, David (2000). Secret-Ballot Receipts And Transparent Integrity,. David Chaum, Draft. Available at http://www.vreceipt.Com/Article.Pdf

[11] Cranor, L. \& Cytron, R. (1997). Sensus: A SecurityConscious Electronic Polling System For The Internet", In Proceedings Of The 30th Annual Hawaii International Conference On System Sciences, Wailea, Hawaii.

[12] Folorunso, O. et al., (2010). Visualizing E-Voting Resultsll, Journal of Theoretical and Applied Information Technology. available at: www.jatit.org

[13] Inec Manual For Election Officials (2015). Funded By The European Union Through The UNDP Democratic Governance For Development (DGD) Project.

14] Kabiru G. (2015)Local Government Elections and Democratic Consolidation in Nigeria, 13(2) JORIND 1

[15] Mohammed D A et al (2013) The Design and Development of Real-Time EVoting System in Nigeria with Emphasis on Security and Result Veracity, I. J. Computer Network and Information Security

[16] Okediran O. et al., (2001). A Framework For A Multifaceted Electronic Voting System, International Journal Of Applied Science And Technology Philadelphia, Usa, Vol. 1 No.4, Pp 135-142; July

[17] Omolaye P. O. (2015) Systemic Evaluation of SemiElectronic Voting System adopted in Nigeria 2015 General Elections, American Journal of Information Systems, Vol. 3, No. 1

[18] Vishal V. N (2014). E-Voting Using Biometric. International Journal Of Emerging Technology And Advanced Engineering www.Ijetae.Com

[19] Yekini, N.A., et al., (2012). Computer-Based Automated Voting Machine (Avm) For Elections In Nigeria. International Journal Of Computer Science And Network Security, Vol.12 No.5, May 2012.

[20] Zissis, D. (April 2011). Securing E-Government And EVoting With An Open Cloud Computing Architecture. Government Information Quarterly 28 (2): 239-251. 